\title{
レーザ照射による超電導体の接合 II
}

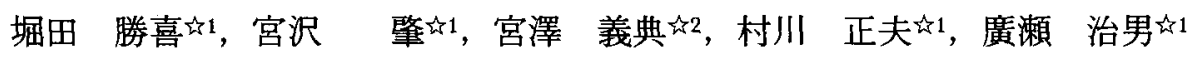 \\ 的1 日本工業大学電気電子工学科， ₹345 埼玉県南埼玉郡宮代町学園台4-1. \\ 江2 日本工業大学大学院, 厂345 埼玉県南埼玉郡宮代町学園台4-1.
}

\section{Connecting Superconductors by Laser Irradiation II}

\author{
Katsuyoshi Hotta ${ }^{\hbar 1}$, Hajime Miyazawa $a^{\hbar 1}$, Yoshinori Miyazawa $a^{\hbar 2}$ \\ Masao Murakawa ${ }^{\hbar 1}$ and Haruo Hirose \\ in Nippon Institute of Technology, 4-1 Gakuendai Miyashiro-machi Minami-Saitama-gun, Saitama 345. \\ \&2 Graduate School, Nippon Institute of Technology, 4-1 Gakuendai Miyashiro-machi \\ Minami-Saitama-gun, Saitama 345.
}

Received September 24, 1996

\section{SYNPOSIS}

A study on connecting superconductors of $Y$ system 123 phase through the laser irradiation treatment has been conducted. Superconductive powder of the identical phase pasted with a mixture of organic binder and solvent were filled as a medium between the two pieces of the superconductive bulk installed on a jig system, and which were set on a $\mathrm{X}-\mathrm{Y}$ table to be irradiated by $\mathrm{CO}_{2}$ laser accompanied by oxygen gas blow along its contact line under the conditions : laser output power $260 \sim 320 \mathrm{~W}$ at defocus distance of focal point $120 \mathrm{~mm}$, assist gas pressure 98 294 $\mathrm{kPa}$, beam scan speed $1 \sim 8 \mathrm{~mm} / \mathrm{min}$, and beam scan times $1 \sim 3$ strokes.

The results indicated that the electric resistance was almost constant before the laser irradiations but $57.9 \mathrm{~K}$ as $\mathrm{Tc}\left(\mathrm{n}_{\mathrm{n}}\right)$ was obtained for the certain samples when blown with a great deal of oxygen gas at low speed beam scans at the laser irradiations. SEM image and EPMA mapping after the laser irradiation showed that the superconductive bulk and the paste were connected successfully.

\section{KEY WORDS}

superconductor, $\mathrm{Y}$ system, connection, laser irradiation

\section{1 粕言}

磁気シールドなどへの応用で超電導バルク材の 大面積化をはかる埸合, プレス成形や電気妒によ る大きさの制限を受ける。著者らは，これまでに 超電導体の大きさが電気妒の大きさに制約されず オープンスペースによる大面積超電導体の作製を
目的として, Bi 系超電導バルク材を $2 つ$ 組み合わ せ,その間の接合部に同系の媒体を入れてレーザ 照射することにより超電導接合は可能であること を示した ${ }^{1-3)}$ 。本報告では，Y系超電導体を用い た場合でも，同様にレーザ照射することによる超 電尊接合は可能でるかを実験検郡した。 


\section{2 実筷方法}

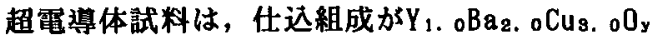
(123組成)で, Tc ( ○只 $=90.5 \mathrm{~K}$ の超電導バルク材を 使用した.このバルク材を治具に納まる5.0X6.0X $2.0 \mathrm{~mm}$ の大きさにカットし，2ピース1組として接 合のための試料とした。また接合部の溶洞として この超電導体を粉末にしたすのと，有機バインダ 一や有機溶郕などで混ぜ合わせた媒質と混合して ペースト状にし，これを超電導ベーストとして接 合面及び接合面上部に塗布した。このとき，接合 面に対して垂直方向から軽くプレスしながら熱伝 導性の良い真銀を台座にした治具に納めた。レー ザはCO2 2 ーザを使用して，図1に示すように， 試料をXーYテーブル上に固定し，アシストガス として酸素をビーム照射口より，レーザと共に吹 き付けながらデフォーカス120ma定として，接 合面に治ってレーザ照射した。このときの照射条 件はレーザ出力260 320州，アシストカスス圧98 294 $\mathrm{kPa} ， ス キ+\nu$ 速度 $1 \sim 8 \mathrm{~mm} / \mathrm{min}$, 照射回数 $1 \sim 3$ 回上 各々変化させて実験を行った．評洒は直流四端子 法による電気抵抗一温度特性, SEM锭察, EPMA分 析により行った.

\section{3 実只拮果並ひた模时}

図 $2 に ， Y$ 系超電導バルク材を治具に超電導接 合用に納めた状態でのレーザ照射前と，アシスト ガス圧を変化させてレーザ照射したときの電気抵 抗一温度特性曲線を示す.レーザ照射前の試料で は超電導接合がなされていないため，接触抵抗と 思われる約 $4.5 \mathrm{k}$ 日一定の值を示すのみであり, 温 度を下げても抵抗值は変化せず温度に対する依存 性はごくわずかであった。しかし，レーザ照射時 に, 出力 280 I， スキャン速度3四/nin, 3回照射を 一定の条件として，アシストガス圧を98,196,294 $\mathrm{kPa}$ 変化させてレーザ照射したところ，低いァ シストガス圧では半導体的特性を示し超電導接合 がなされていないが，アシストガス圧を高くする に従い超電導接合がなされ，Tc(end)はアシスト ガス压と共に高くなる㑯向を示している。そこで この結果を基に高いアシストカスス圧 $294 \mathrm{kPa}$ 一定 の条件として，スキャン速度を変化させて実馀を 行った.

図3に，スキャン速度を変化させレーザ照射し たときの電気抵抗一温度特性曲線を示す。レーザ 照射時の条件を前実験と同じように出力 280 ，了 シストガス圧 $294 \mathrm{kPa} ， 3$ 回盟射を一定の条件とし スキャン速度を8,5,3mm/minと変化させてレーザ 照射したところ，速度が速いときは超電導接合が なされていないが，スキャン速度を遅くするに徉 いTc (ond)は35Kから42Kと高くなる傾向を示して いる.

アシストガス圧変化及びスキャン速度变化のレ ーザ照射後の結果より，アシストガス圧を高くし

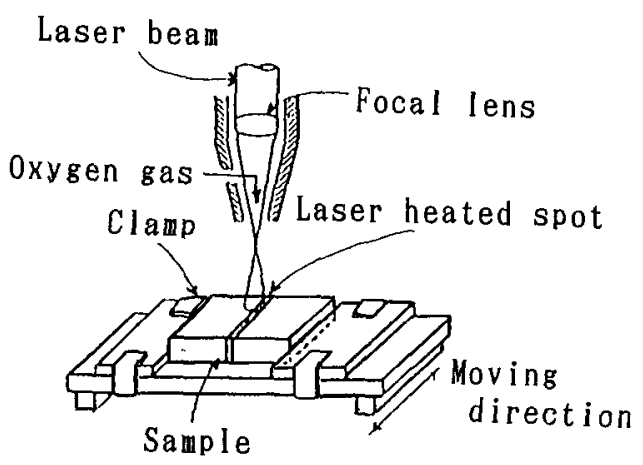

Fig.1 Set-up for laser irradiation.

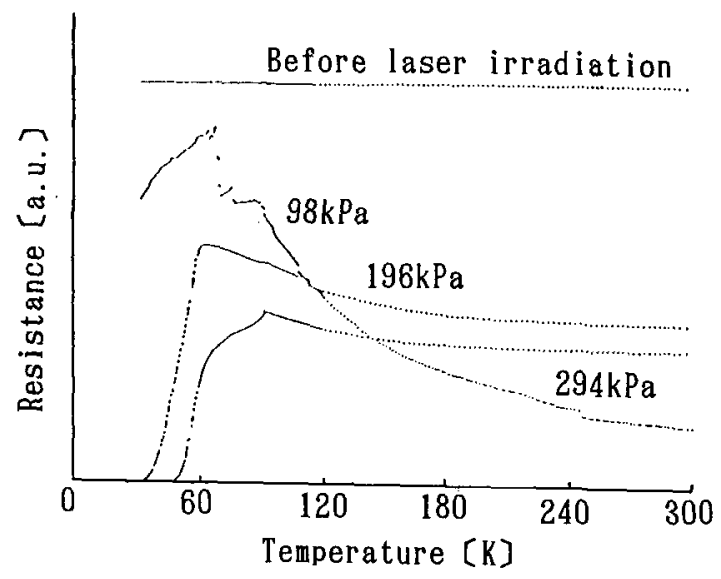

Fig.2 Resistance vs. temperature for 123 $Y$ system before and after laser irradiation with changing assist gas pressure.

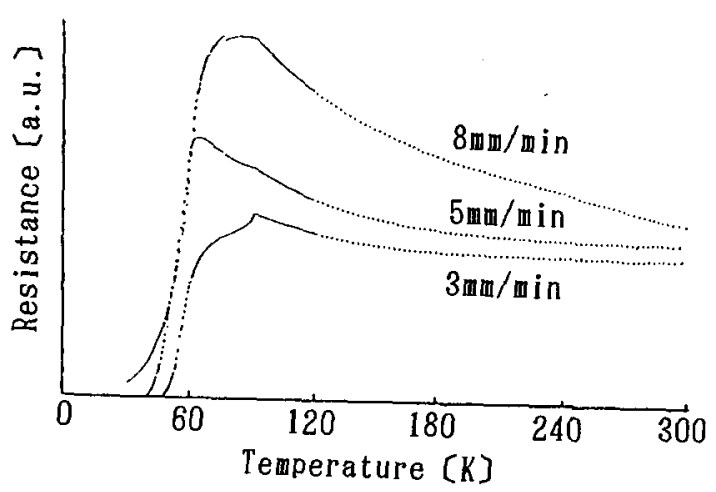

Fig.3 Resistance vs. temperature for 123 $Y$ system after laser irradiation with changing beam scan speed. 
スキャン速度を遅くしてレーザ照射することによ り, Tc ( n nd) が高くなる傾向があることが分かっ た.そこで更に遅いスキャン速度 $1 \mathrm{~mm} / \mathrm{min}$ として $294 \mathrm{kPa}$ の高ガス圧でレーザ出力を260 320変化 させて1回照射として実験を行った．これを図 4 に電気抵抗一温度特性曲線を示すと, 出力 300 界で $300 \mathrm{~K}$ のきの電気抵抗は約 $110 \mathrm{~m}$ 亿非常に小さく なり, 93K付近でTc (onset) を示し, 抵抗の値は急 激に減少し，75K付近からその後長く尾を引き， Tc(ond) は57.9Kが得られた。しかし，これよりも 低出力または高出力では, 300Kのときの電気抵抗 は約190 1400m凤で, 93K付近でTc (onst)が見られ るむのの, まだ粒子間の超電導結合があまり良く なく Tc (ond) は40 50Kにとどまった.これらより， 出力300界において低速度で多量の酸素ガスを吹き 付けながらレーザ照射することにより, 接合状態 が良くなったむのと思われる，また，むっと最適 な照射条件を見つければ, Tc ( ond) は長く尾を引

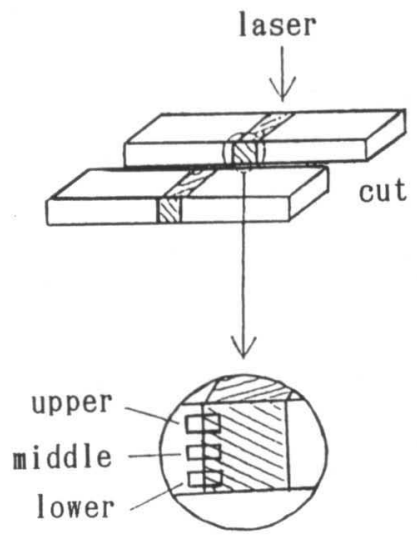

a) Schematics of cross sectional view of connected portion

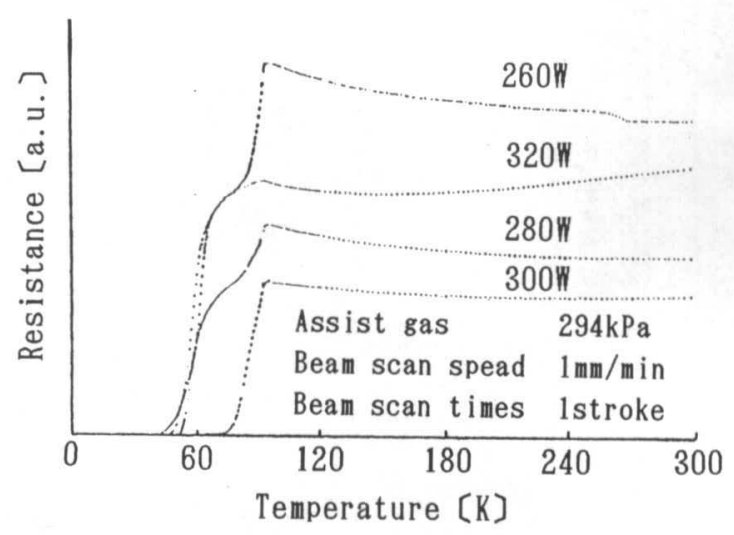

Fig. 4 Resistance vs. temperature for 123 $Y$ system after laser irradiation with changing output power.

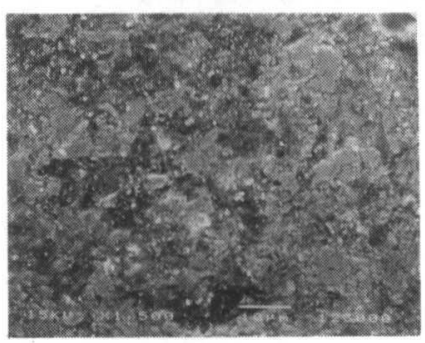

b) upper part

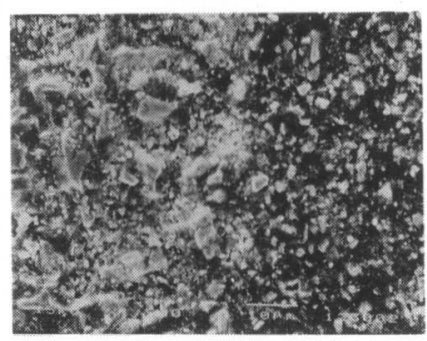

c) middle part

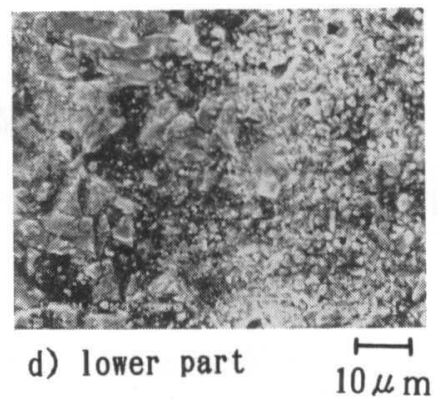

Fig. 5 SEM image of each part at the cross section of the connecting part for the $Y$ system cut of by using diamond cutter after laser irradiation (no etching). 


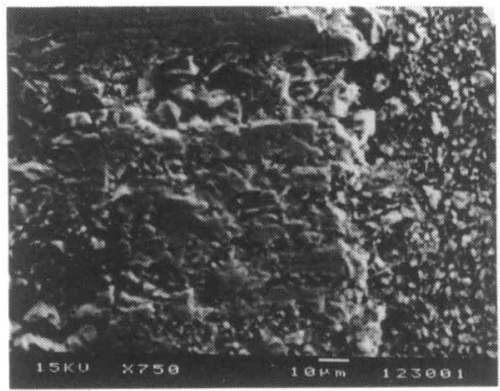

SEM images

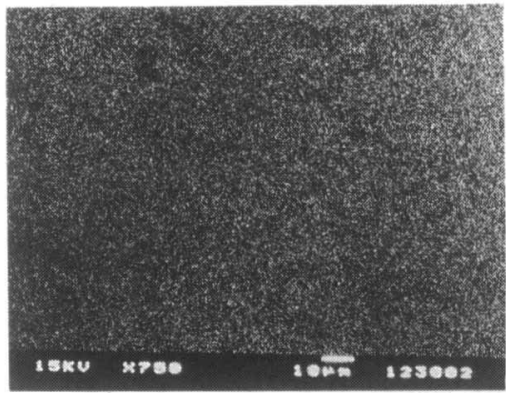

$\mathrm{Ba}$

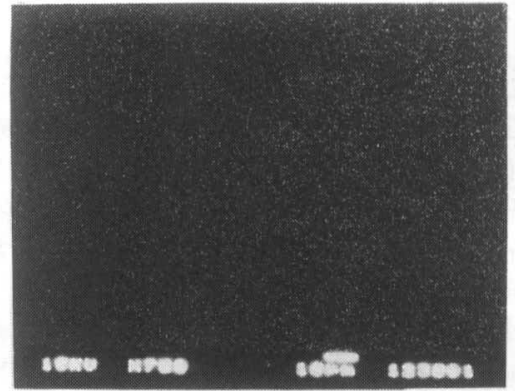

Y

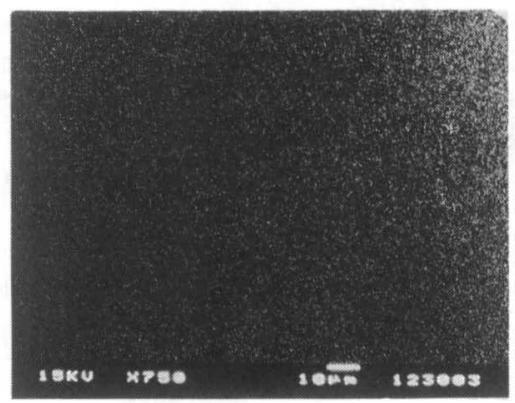

$\mathrm{Cu}$

$10 \mu \mathrm{m}$

Fig. 6 SEM images and EPMA mapping of elements at the cross section portion after laser irradiation.

かず70 75Kで得られるむのと考えている. その理 由はレーザ照射によるペースト材部分の組成が少 し違っているように思われるからである。

図5にレーザ照射して超電導接合された試料の SEM写真を示す.（a)の斜線部分が超電導ペースト 部分であり，レーザ照射した試料を接合面に対し て垂直にダイヤモンドカッターで切断した．この ときこの観察面はカットしたままで,エッジング などの処理は何す行っていない. 上から順に, レ 一ザ照射した表面の近くの接合状態, 中心部, そ して底部を示している. 左側が超電導バルク材部 分で，右側がペースト材部分であり，接合面をは さむように钼察している. 表面に近い部分では, バルク材部分とペースト材部分の境界が分からな いほどに非常に良く超電導接合がなされている. 中心部では, 接合がされているがペースト材部分 に粒径状のものが少し見られている. また底部で は, 真鍮の台座に近いためか熱がこもり，中心部 より良く接合している.

図6にレーザ照射して超電導接合された試料の EPMA分析写真を示す. 左側が超電導バルク材部分 であり, 右側が超電導ペースト材部分である. 超 電導接合されたSEM写真のイメージを基に, Baは
バルク材部分とペースト材部分に均一に分布され ていることが観察され，YとCuは若干の偏析が見 られペースト材部分が少しリッチに観察されてい るが, 接合状態としては良いすのと思われる.

\section{4 結詥}

1.Y系超電導体です, 同一組成の超電導バルク間 に超電導ペーストをはさみ，レーザ照射するこ とにより超電導接合が可能となった。

2. 低速度で多量の酸素を吹き付けながらレーザ照 射することにより達成された接合部のTc (•nd) は57.9Kであった.

3. 接合部のTc(end)は，70 75Kが得られる可能性 を示した.

\section{文献}

1) 宮沢, 堀田, 船戸, 村川, 廣瀬 : 粉体および 粉末治金, 41(1994)PP. 1516-1519.

2) K. Hot ta, H. Miyazawa, K. Funa to, M. Murakawa and H.Hirose:Physica C 235-240 (1994) PP. 3429-3430.

3）堀田, 宮沢, 小川, 村川, 廣瀬 : 粉体および 粉末冶金, 42(1995)PP. 821-824. 